\title{
ANALISIS ARSIP KERJASAMA STIKES MUHAMMADIYAH GOMBONG DENGAN PERGURUAN TINGGI DI LUAR NEGERI
}

\author{
Desy Setiyawati ${ }^{(1)}$, Sri Rohyanti Zulaikha ${ }^{(2)}$ \\ 1,2 UIN Sunan Kalijaga Yogyakarta \\ email: dessysetiyawati@gmail.com
}

\begin{abstract}
Abstrak
Kajian ini bertujuan untuk mengetahui pelaksanaan kerjasama antara STIKES Muhammadiyah Gombong dengan perguruan tinggi di luar negeri dari khazanah arsip dan manfaat arsip dalam kegiatan tersebut. STIKES Muhammadiyah Gombong, sebagai salah satu perguruan tinggi dituntut untuk bisa menciptakan sumber daya manusia (SDM) yang siap bersaing dan berkompetisi di era global. Salah satu cara yang dilakukan adalah melakukan kerjasama dengan perguruan tinggi di luar negeri. Metode yang digunakan dalam kajian ini adalah metode deskriptif yaitu mengkaji fenomena secara lebih rinci atau membedakannya dengan fenomena yang lain. Sedangkan Teknik pengumpulan datanya menggunakan teknik dokumentasi. Dalam hal ini Penulis lebih menekankan pada sumber arsip dinamis dan statis dari kebijakan pemerintah serta arsip yang ada di STIKES Muhammadiyah Gombong. Dari hasil analisis diketahui bahwa arsip sangat berperan dalam pelaksanaan kerjasama di STIKES Muhammadiyah Gombong. Sudah banyak kerjasama dan kegiatan yang dilakukan antara STIKES Muhammadiyah Gombong dengan perguruan tinggi di luar negeri. Hal tersebut penulis peroleh melalui arsip yang ada di STIKES Muhammadiyah Gombong. Dengan arsip tersebut bisa diketahui perkembangan kerjasama yang telah dilakukan dan bisa dijadikan sebagai alat ukur bagi pelaksanaan kerjasama selanjutnya.
\end{abstract}

\author{
Kata Kunci: \\ arsip, \\ kerjasama, \\ luar negeri, \\ perguruan tinggi
}

\section{A. PENDAHULUAN}

Salah satu tujuan pendidikan tinggi adalah menghasilkan lulusan yang menguasai cabang ilmu pengetahuan dan/atau teknologi untuk memenuhi kepentingan nasional dan peningkatan daya saing bangsa (R. Indonesia, 2012). Perguruan tinggi sebagai salah satu lembaga pendidikan yang bertujuan mencetak sumber daya manusia (SDM) yang unggul senantiasa berusaha untuk menyiapkan SDM agar bisa bersaing secara global. Apalagi setelah diterapkannya Masyarakat Ekonomi Asean (MEA) sejak tahun 2015. Sebagai tindak lanjut MEA 2015, dicanangkan MEA 2025 yang bertujuan untuk membuat ekonomi ASEAN semakin terintegrasi dan kohesif; berdaya saing dan dinamis; peningkatan konektivitas dan kerja sama sektoral; tangguh, inklusif, berorientasi serta berpusat pada masyarakat; serta ASEAN yang global (K. L. N. R. Indonesia, 2015).

Salah satu isu yang mengemuka terkait dengan implementasi MEA yaitu kesiapan SDM. Karena MEA tidak hanya membuka arus perdagangan dan jasa namun juga pasar tenaga kerja profesional, seperti dokter, pengacara, akuntan dan lain sebagainya. Dilihat dari sisi pendidikan dan produktivitas, Indonesia masih kalah bersaing dengan tenaga kerja yang berasal dari Malaysia, Singapura dan Thailand (Wuryandari, 2015). Hal tersebut menjadi tantangan tersendiri bagi perguruan tinggi di Indonesia.

Sementara itu, Indonesia sebagai bagian dari masyarakat global dituntut untuk selalu meningkatkan hubungan dengan masyarakat dunia. Untuk meningkatkan daya saing perguruan tinggi Indonesia dengan perguruan tinggi luar 
negeri, kita perlu memperhatikan peningkatan kualitas perguruan tinggi dengan serius. Salah satu cara supaya peningkatan kualitas perguruan tinggi dapat tercapai dengan cepat yaitu dengan menjalin kerjasama dengan perguruan tinggi luar negeri yang mempunyai reputasi baik (Nayono, 2012). Penyelenggaraan program kerja sama perguruan tinggi Indonesia tertuang dalam Peraturan Menteri Pendidikan dan Kebudayaan RI Nomor 14 Tahun 2014 tentang Kerjasama Perguruan Tinggi. Dalam peraturan itu disebutkan bahwa kerjasama perguruan tinggi bertujuan meningkatkan efektivitas, efisiensi, produktivitas, kreativitas, inovasi, mutu dan relevansi pelaksanaan Tridharma Perguruan Tinggi untuk meningkatkan daya saing bangsa (Peraturan Menteri Pendidikan dan Kebudayaan Republik Indonesia, 2014).

Berpijak dari hal tersebut, Sekolah Tinggi Ilmu Kesehatan (STIKES) Muhammadiyah Gombong yang merupakan satu-satunya perguruan tinggi kesehatan dari tujuh perguruan tinggi di Kabupaten Kebumen Provinsi Jawa Tengah berupaya melakukan kerjasama dengan beberapa perguruan tinggi di luar negeri. STIKES Muhammadiyah Gombong berdiri sejak tahun 1994 dengan nama Akademi Keperawatan (AKPER) Muhammadiyah Gombong. Sudah banyak prestasi yang diraih oleh STIKES Muhammadiyah Gombong. Hal tersebut sesuai dengan visinya yaitu menjadikan lembaga pendidikan kesehatan yang unggul, modern dan Islami (Gombong, n.d.).

Kajian mengenai kerjasama dengan luar negeri sebelumnya pernah dilakukan oleh Dharwis Widya Utama Yacob yang berjudul Mengungkap Hubungan Diplomasi Indonesia-Tiongkok dari Khazanah Arsip Statis. Dalam kajian tersebut membahas tentang hubungan diplomasi antara Indonesia-Tiongkok yang berkembang dengan positif dimana kerjasama tersebut terjadi karena beberapa faktor, antara lain perdagangan, agama, serta politik. Perkembangan hubungan diplomasi antara kedua negara tersebut dapat dibuktikan dengan arsip yang bisa dilihat dari khazanah arsip statis. Arsip tersebut tersimpan di Arsip Nasional Republik Indonesia (ANRI) dan dapat diakses oleh peneliti maupun pengguna yang membutuhkannya (Yacob, 2016). Akan tetapi, dalam kajian tersebut belum membahas pemanfaatan arsip dalam kerjasama bidang pendidikan dan hanya terbatas hubungan antar dua negara saja. Sedangkan arsip merupakan bukti dan rekaman kegiatan atau transaksi mulai dari kegiatan terdepan sampai pada kegiatan-kegiatan pengambilan keputusan. Dalam setiap pekerjaan dan kegiatan dan organisasi, memerlukan data dan informasi. Salah satu sumber datanya yaitu arsip (Hendrawan \& Ulum, 2018).

Oleh karena itu, Penulis ingin mengkaji kerjasama antara Indonesia dengan luar negeri khususnya dalam bidang pendidikan pada perguruan tinggi melalui arsip. Dan STIKES Muhammadiyah Gombong telah melakukan kerjasama dengan luar negeri sebagai salah satu cara untuk mewujudkan visi institusi dan sarana dalam mengimplementasikan kebijakan pemerintah agar bisa bersaing di era global. Dari latar belakang tersebut, Penulis tertarik untuk menganalisis arsip kerjasama STIKES Muhammadiyah Gombong dengan perguruan tinggi di luar negeri.

\section{B. KAJIAN TEORITIS}

\section{Arsip Perguruan Tinggi}

Dalam Undang-Undang Kearsipan Republik Indonesia Nomor 43 Tahun 2009 tentang Kearsipan disebutkan bahwa arsip perguruan tinggi adalah lembaga kearsipan perguruan tinggi; Perguruan Tinggi Negeri wajib membentuk arsip perguruan tinggi; pembentukan arsip perguruan tinggi dilaksanakan sesuai dengan ketentuan perundang-undangan dan arsip perguruan tinggi wajib melaksanakan pengelolaan arsip statis yang diterima dari satuan kerja dan civitas akademika di lingkungan perguruan tinggi (Undang-Undang 
Republik Indonesia Nomor 43 Tahun 2009 tentang Kearsipan, 2009). Kinerja perguruan tinggi sebagai organisasi atau institusi dapat dilihat dari arsip yang dimiliki. Perguruan tinggi sebagai lembaga pendidikan tinggi mempunyai dokumen administrasi dan akademis serta banyak menghasilkan dokumen karya ilmiah (dokumen vital, penting dan berguna) (Damalita, 2009). Oleh karena itu, peran arsip sangat penting dalam perguruan tinggi.

Fungsi unit arsip di perguruan tinggi adalah untuk mengelola dan menyelamatkan dokumen/ arsip dengan:

1. Mengembangkan pelestarian arsip arsip statis/ dokumen bernilai guna permanen untuk kepentingan layanan publik

2. Melaksanakan pengembangan sistem kearsipan dinamis

3. Melaksanakan pemeliharaan, pengawasan, perawatan arsip inaktif dan arsip statis

4. Menyelenggarakan penyelamatan sumbersumber kearsipan

5. Melaksanakan transkripsi dan transliterasi arsip

6. Menyelenggarakan alih media dan otomasi arsip

7. Melaksanakan pemasyarakatan/publikasi kearsipan (Damalita, 2009).

Dalam arsip akademik, program manajemen arsip dinamis adalah bagian yang krusial. Arsiparis dituntut untuk bisa bekerjasama dengan para unit kerja di lingkungan perguruan tinggi dalam menjamin keutuhan arsipnya karena hulu dari arsip akademik adalah pengelolaan arsip dinamis yang praktiknya ada di berbagai unit kerja (Suprayitno, 2017). Mengingat banyaknya fungsi unit kearsipan dan pentingnya arsip di perguruan tinggi, STIKES Muhammadiyah Gombong berusaha melakukan kearsipan dengan baik. Saat ini, di masing-masing unit ada staf administrasi yang juga bertugas sebagai pengelola arsip dalam unitnya masing-masing sehingga kearsipan menjadi lebih terkontrol.

\section{Kerjasama Perguruan Tinggi}

Dalam meningkatkan daya saing perguruan tinggi di dunia internasional, diperlukan SDM yang kompeten dan profesional. Berdasarkan data tahun 2019, indeks pendidikan Indonesia rendah. Hal tersebut bisa kita lihat dalam tabel berikut:

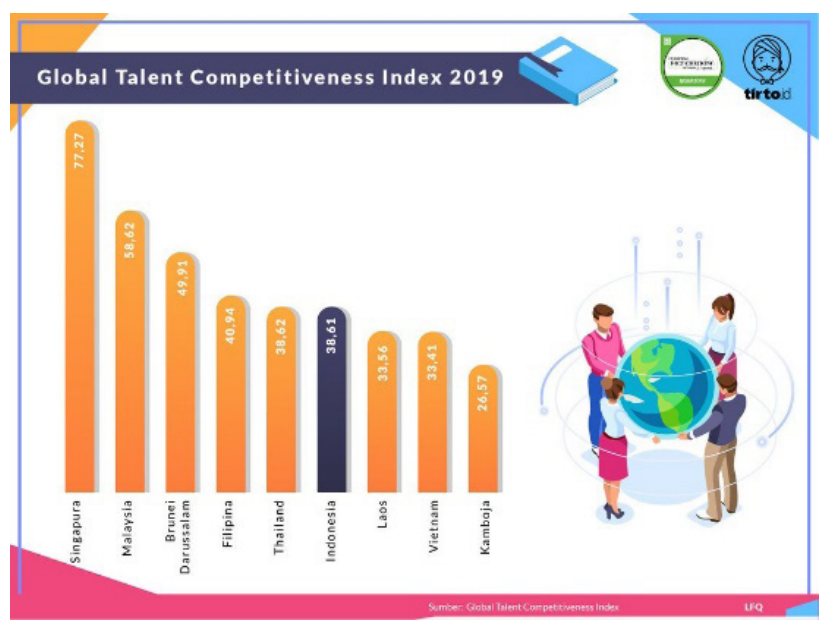

indeks daya saing bakat global tahun 2019

Data tersebut dirilis oleh INSEAS yang menyusun pemeringkatan dengan penekanan penting pada pendidikan. Dengan rendahnya indeks pendidikan, rendah pula daya saingnya (Gerintya, 2019). Salah satu cara untuk meningkatkan pendidikan di Indonesia khususnya di perguruan tinggi adalah diperoleh melalui kerjasama dengan stakeholder. Stakeholder adalah suatu masyarakat, kelompok, komunitas ataupun individu manusia yang memiliki hubungan dan kepentingan terhadap suatu organisasi atau perusahaan (N., 2015). Kerjasama perguruan tinggi sudah mempunyai landasan hukum yaitu Peraturan Menteri Pendidikan dan Kebudayaan RI No. 14 Tahun 2014 Pasal 7 sampai Pasal 22 tentang Kerjasama Perguruan Tinggi. Sedangkan pedoman teknis penyelenggaraan kerjasama tersebut diatur dalam beberapa undang-undang. Undang-undang tersebut antara lain Undang-Undang No. 20 Tahun 2003 tentang Sistem Pendidikan Nasional (Lembaran Negara Republik Indonesia Tahun 2003 Nomor 78, Tambahan Lembaran Negara Republik Indonesia Nomor 4301), Undang-Undang No. 12 
Tahun 2012 tentang Pendidikan Tinggi dan UndangUndang Nomor 14 Tahun 2005 tentang Guru dan Dosen. Dalam undang-undang tersebut dijelaskan mengenai pedoman teknis penyelenggaraan kerjasama perguruan tinggi Indonesia dengan perguruan tinggi atau lembaga lain di dalam dan luar negeri (Kementerian Riset, 2019).

Dasar kerjasama yang diselenggarakan oleh perguruan tinggi didasarkan pada rencana strategis dan statuta perguruan tinggi masing-masing. Kerjasama bidang akademik dengan perguruan tinggi lain, baik di dalam maupun di luar negeri dilakukan melalui modus penawaran dan/atau permintaan yang yang diselenggarakan dengan pola:

1. Pembimbing-dibimbing, dan/atau

2. Kolaborasi

(Kementerian Riset, 2019)

Hal itu dilakukan agar para pihak yang melakukan kerjasama tidak ada yang merasa dirugikan.

Kerjasama dalam bidang pendidikan tinggi yang diusung dalam pertemuan APEC (Asian Pacific Economies Cooperation) tentang "Cross-border Education on Higher Education" meliputi peningkatan mobilitas mahasiswa, peningkatan mobilitas peneliti, peningkatan mobilitas pemberi layanan pendidikan (educator providers) dan peningkatan jejaring kesepakatan bilateral yang sudah ada (Kementerian Riset, 2015). Kerjasama sangat penting dilakukan untuk bisa berkompetisi dengan perguruan tinggi lain terutama perguruan tinggi di luar negeri. Kerjasama bisa dilakukan dalam bentuk studi banding, workshop, seminar, magang maupun pertukaran mahasiswa/dosen/tenaga kependidikan.

\section{METODE}

Metode yang digunakan dalam kajian ini adalah metode deskriptif yaitu mengkaji fenomena secara lebih rinci atau membedakannya dengan fenomena yang lain. Sedangkan Teknik pengum- pulan datanya menggunakan teknik dokumentasi yaitu mencari data tentang hal-hal atau variabel yang berupa catatan, transkrip, buku, surat kabar, majalah, prasasti, notulen rapat, agenda, dan sebagainya (Siyoto \& Sodik, 2015). Penulis lebih menekankan pada penggunaan sumber arsip dinamis dan statis dari kebijakan pemerintah serta arsip yang ada di STIKES Muhammadiyah Gombong.

\section{HASIL DAN PEMBAHASAN}

\section{Kerjasama STIKES Muhammadiyah Gombong dengan Perguruan Tinggi di Luar Negeri}

Landasan hukum yang mendukung kerjasama internasional dalam bidang pendidikan tinggi di Indonesia adalah Undang-Undang Pendidikan Tinggi Nomor 12 Tahun 2012 Pasal 50 dan Pasal 90 serta dalam Peraturan Menteri Pendidikan dan Kebudayaan RI Nomor 14 Tahun 2014 tentang Kerjasama. Berdasarkan landasan hukum tersebut, STIKES Muhammadiyah Gombong juga melakukan kerjasama internasional dengan beberapa perguruan tinggi di luar negeri. Arsip kerjasama internasional ini bisa diperoleh dari koleksi arsip yang ada di Bagian Humas STIKES Muhammadiyah Gombong dan arsip elektronik, baik online maupun offline. Dari arsip offline berjumlah 19 arsip sedangkan dari arsip online berjumlah 6 arsip. Berdasarkan analisis arsip-arsip tersebut, diperoleh informasi sebagai berikut:

Pada tahun 2017, STIKES Muhammadiyah Gombong melakukan kerjasama dengan dua universitas di Jepang. Dua universitas tersebut yaitu International University of Health and Welfare (IUHW) di Narita dan JICHI Medical University. Kerjasama diawali dengan STIKES Muhammadiyah Gombong bersama 38 delegasi perguruan tinggi Muhammadiyah mengadakan kunjungan ke Jepang. Selain merintis kerjasama internasional, STIKES Muhammadiyah Gombong juga belajar mengenai sistem pendidikan seperti kurikulum, 
teknologi, SDM dan rumah sakit. Usai kunjungan tersebut akan ditindaklanjuti dengan kunjungan balasan (Gombong, 2017).

Sedangkan di tahun 2018, STIKES Muhammadiyah Gombong mengadakan kunjungan ke Faculty of Nursing (FoN) Khon Kaen University of Thailand. Pada tanggal 2-7 Juli 2018, sebanyak 18 mahasiswa Program Profesi Ners mengikuti field trip ke Thailand. Kegiatan tersebut dalam rangka meningkatkan kompetensi di bidang keperawatan yaitu dengan melihat dan membandingkan secara langsung mengenai pelayanan di pusat kesehatan masyarakat di Thailand. Tidak sekedar melakukan kunjungan, para mahasiswa juga melakukan presentasi dari hasil kunjungan selama seminggu di Khon Kaen University dan evaluasi. Kunjungan ke Thailand tersebut juga dalam rangka memperbarui nota kesepahaman yang sudah dilakukan selama ini. Kerjasama yang sudah dilakukan STIKES Muhammadiyah Gombong dengan Khon Kaen University antara lain, joint research; students, staff and lecturer program; serta seminar dan pelatihan bersama untuk kedua belah pihak dalam rangka mewujudkan visi dan misi dari masing-masing institusi (Gombong, 2018). Selain beberapa hal yang sudah dilakukan diatas, 4 dosen dari STIKES Muhammadiyah Gombong melaksanakan studi lanjut di Khon Kaen University. Dua orang studi lanjut S2 dan dua orang studi lanjut S3.

Selain Jepang dan Thailand, kerjasama juga dilakukan dengan sejumlah perguruan tinggi di Malaysia, Filipina dan China. Pada tahun 2019, sebanyak enam orang mahasiswa STIKES Muhammadiyah Gombong mengikuti International Nursing Student Forum di University Malaysia Sarawak (Unimas) Malaysia. Tidak hanya sebagai peserta, tetapi mereka juga menjadi panitia bergabung dengan sejumlah perguruan tinggi di luar negeri. Selain kunjungan ke Unimas, juga ada kegiatan eksekutif meeting dalam rangka melakukan penjajakan kerjasama antara STIKES Muham- madiyah Gombong dengan Unimas Malaysia. Rencana kerjasama tersebut antara lain pertukaran mahasiswa, studi lanjut S2 dan S3 hingga joint research (Gombong, 2019). Kegiatan ini adalah adalah wujud dari pelaksanaan kerjasama STIKES Muhammadiyah Gombong dengan perguruan tinggi di luar negeri.

\section{Manfaat Arsip dalam Kegiatan Kerjasama}

Beberapa informasi kerjasama seperti yang telah dikemukakan di atas diperoleh dari dokumen arsip STIKES Muhammadiyah Gombong yang ada di Bagian Humas. Salah satu tugas Bagian Humas adalah di bidang kerjasama antara STIKES Muhammadiyah Gombong dengan pihak lain. Bagian Humas juga bertugas mengelola arsip yang berhubungan dengan kerjasama, baik arsip online maupun offline. Dari arsip kerjasama tersebut bisa diketahui perkembangan kerjasama STIKES Muhammadiyah Gombong yang hasilnya bisa dijadikan sebagai alat ukur dalam melakukan kerjasama selanjutnya.

Dalam melakukan kerjasama, banyak dokumen arsip yang harus disiapkan seperti MoU, bukti izin operasional institusi, bukti status akreditasi, profil institusi atau program studi dan dokumen pendukung lainnya. Kerjasama tidak bisa dilakukan jika dokumen-dokumen yang diperlukan hilang. Oleh karena itu, pengelolaan arsip yang baik di perguruan tinggi sangatlah vital. Perguruan tinggi mempunyai banyak dokumen penting sebagai bukti rekaman kegiatan civitas akademika.

Bukan hanya arsip-arsip untuk persyaratan kerjasama saja yang kita jaga, tetapi juga arsip-arsip pelaksanaan dan hasil kerjasama institusi harus dikelola dengan baik. Tanpa arsip-arsip tersebut, kegiatan kerjasama akan mengalami kendala dalam perjalannya. Arsip online akan memudahkan kita dalam temu kembali arsip agar kegiatan arsip bisa berjalan lebih cepat.

Karena adanya arsip, kegiatan kerjasama STIKES Muhammadiyah Gombong dengan beberapa 
perguruan tinggi di luar negeri bisa terekam dengan baik. Diharapkan rekaman tersebut bisa menjadi acuan dalam melakukan kerjasama selanjutnya sehingga bisa menciptakan SDM yang bisa bersaing dan berkompetisi di era global serta siap menghadapi Masyarakat Ekonomi ASEAN (MEA). Pengelolaan arsip yang baik perlu dipertahankan dan ditingkatkan agar menjadi budaya dalam pengelolaan arsip di setiap instansi. Kebiasaan yang positif akan menghasilkan hasil yang positif pula.

\section{E. PENUTUP \\ Simpulan}

Kinerja perguruan tinggi sebagai organisasi atau institusi dapat dilihat dari arsip yang dimiliki. Sebagai salah satu perguruan tinggi, STIKES Muhammadiyah Gombong dituntut untuk dapat menciptakan SDM yang unggul dan bisa bersaing dan berkompetisi di era global. Untuk mewujudkan hal tersebut, STIKES Muhammadiyah melakukan kerjasama dengan beberapa perguruan tinggi di luar negeri.

Ada beberapa perguruan tinggi di luar negeri yang sudah bekerjasama dengan STIKES Muhammadiyah Gombong antara lain International University of Health and Welfare (IUHW) di Narita dan JICHI Medical University di Jepang, Faculty of Nursing (FoN) Khon Kaen University di Thailand, Unimas Malaysia dan beberapa perguruan tinggi lainnya. Banyak kegiatan yang telah dilakukan dalam kerjasama-kerjasama tersebut seperti joint research; students, staff and lecturer program; serta seminar dan pelatihan bersama untuk kedua belah pihak.

Beberapa informasi kerjasama tersebut bisa diketahui karena adanya arsip yang dikelola dengan baik. Arsip tersebut ada yang bisa diakses secara online dan ada yang hanya bisa diakses secara offline. Apapun bentuknya, arsip merupakan hal yang sangat vital bagi perguruan tinggi mengingat banyaknya dokumen yang dihasilkan dari perguruan tinggi. Dengan adanya arsip kerjasama tersebut bisa dijadikan sebagai alat ukur pelaksanaan kegiatan kerjasama selanjutnya.

\section{F. DAFTAR PUSTAKA}

Damalita, S. (2009). Pentingnya Manajemen Arsip di Lingkungan Perguruan Tinggi. Jurnal Ekonomi Manajemen, 3(1), 1-10. http://library.um.ac. id/images/stories/arsiparis_um/pentingnya manajemen arsip di lingkungan perguruan tinggi - susiasih d.pdf

Gerintya, S. (2019). Indeks Pendidikan Indonesia Rendah, Daya Saing pun Lemah. Berita. https:// tirto.id/indeks-pendidikan-indonesia-rendahdaya-saing-pun-lemah-dnvR

Gombong, S. M. (n.d.). Profil STIKES Muhammadiyah Gombong. Diambil 25 Maret 2020, dari http:// stikesmuhgombong.ac.id/profil/visi-dan-misi-kami/

Gombong, S. M. (2017). STIKES Muhammadiyah Gombong Jajaki Kerja Sama dengan Dua Universitas di Jepang. http://stikesmuhgombong.ac.id/stikes-muhammadiyah-gombong-jajaki-kerja-sama-dengan-dua-universitas-di-jepang/

Gombong, S. M. (2018). Mahasiswa STIKES Muhammadiyah Gombong Field Trip ke Khon Kaen University Thailand. Berita. http://stikesmuhgombong.ac.id/mahasiswa-stikes-gombongfield-trip-ke-khon-kaen-university-thailand/

Gombong, S. M. (2019). Enam Mahasiswa STIKES Muhammadiyah Gombong Ikuti INSF di Unimas Malaysia. Berita. http://stikesmuhgombong. ac.id/enam-mahasiswa-stikes-gombong-ikuti-insf-di-unimas-malaysia/

Hendrawan, M. R., \& Ulum, M. C. (2018). Pengantar Kearsipan: dari isu kebijakan ke manajemen. UB Press.

Indonesia, K. L. N. R. (2015). Masyarakat Ekonomi ASEAN (MEA). https://kemlu.go.id/portal/id/ read/113/halaman_list_lainnya/masyarakatekonomi-asean-mea 
Peraturan Menteri Pendidikan dan Kebudayaan Republik Indonesia, 1 (2014). http:// Ildikti3.ristekdikti.go.id/html/wp-content/ uploads/2011/04/permen_tahun2014_ nomor014.pdf

Undang-Undang Republik Indonesia Nomor 43 Tahun 2009 tentang Kearsipan, Pub. L. No. 43 (2009). https://peraturan.bpk.go.id/Home/ Details/38788/uu-no-43-tahun-2009

Indonesia, R. (2012). Undang-Undang Republik Indonesia Nomor 12 Tahun 2012 tentang Pendidikan Tinggi. http://sumberdaya.ristekdikti. go.id/wp-content/uploads/2016/02/uu-nomor-12-tahun-2012-ttg-pendidikan-tinggi.pdf Kementerian Riset, T. dan P.T. (2015). Pengembangan Kerjasama Perguruan Tinggi dalam menghadapi Masyarakat Ekonomi ASEAN Masyarakat Ekonomi Asean. http://www.pdpersi.co.id/ diknakes/data/penyelenggaraan_pendidikan/ pengembangan_kerjasama_ristekdikti.pdf

Kementerian Riset, T. dan P. T. (2019). Pedoman Teknis Penyelenggaraan Program Kerja Sama Perguruan Tinggi Indonesia dengan Perguruan Tinggi atau Lembaga Lain di Dalam dan Luar Negeri. Kementerian Riset, Teknologi dan Pendidikan Tinggi. https://www.lldikti4.or.id/ wp-content/uploads/2019/05/PEDOMAN-kerma-May-2016_rev.pdf

N., S. (2015). Sekilas Pengertian Stakeholder dan Contohnya Secara Umum. http://www.pengertianku.net/2015/11/sekilas-pengertian-stakeholder-dan-contohnya-secara-umum.html

Nayono, S. E. (2012). Kerjasama Internasional Perguruan Tinggi: pengalaman di Universitas Negeri Yogyakarta. http://staff.uny.ac.id/ sites/default/files/pengabdian/satoto-endarnayono/strategi-internasionalisasi.pdf

Siyoto, S., \& Sodik, M. A. (2015). Dasar Metodologi Penelitian (Ayup (ed.)). Literasi Media Publishing.
Suprayitno. (2017). Resensi "Academic archives: managing the next generation of college and university archives, records, and special collections." Khazanah: jurnal pengembangan kearsipan, 10(1). https://jurnal.ugm.ac.id/ khazanah/article/view/24752/16038

Wuryandari, D. (2015). Peluang dan Tantangan SDM Indonesia Menyongsong Era Masyarakat Ekonomi ASEAN. Info Singkat Ekonomi dan Kebijakan Publik: kajian singkat terhadap isu-isu terkini, VI(17), 13-16. https://berkas.dpr.go.id/ puslit/files/info_singkat/Info Singkat-VI-17-IP3DI-September-2014-37.pdf

Yacob, D. W. U. (2016). Mengungkap Hubungan Diplomasi Indonesia-Tiongkok dari Khazanah Arsip Statis. ANRI Jurnal Kearsipan, 11(1), 51-64. http://jurnalkearsipan.anri.go.id/index.php/ ojs/issue/view/5 